\title{
Biochemical markers of smoke absorption and self reported exposure to passive smoking
}

\author{
$M$ JARVIS, ${ }^{1}$ H TUNSTALL-PEDOE ${ }^{2}$ C FEYERABEND, ${ }^{3}$ C VESEY, ${ }^{4}$ AND \\ SALLOOJEE4
}

From the Addiction Research Unit, ${ }^{1}$ Institute of Psychiatry,101 Denmark Hill, London SE5 8AF, Cardiovascular Epidemiology Unit, ${ }^{2}$ Ninewells Hospital and Medical School, Dundee, Poisons Unit, ${ }^{3}$ New Cross Hospital, London SE14, and Anaesthetics Laboratory, ${ }^{4}$ St Bartholomew's Hospital, London EC1

SUMMARY One hundred non-smoking patients attending hospital outpatient clinics reported their degree of passive exposure to tobacco smoke over the preceding three days and provided samples of blood, expired air, saliva, and urine. Although the absolute levels were low, the concentration of cotinine in all body compartments surveyed was systematically related to self reported exposure. Salivary nicotine concentration also showed a linear increase with degree of reported exposure, although this measure was sensitive only to exposure on the day of testing. Measures of carbon monoxide, thiocyanate, and plasma nicotine concentrations were unrelated to exposure. The data indicate that cotinine provides a valid marker of the dose received from passive smoke exposure. The non-invasive samples of urine and saliva are particularly suited to epidemiological investigations. Detailed questionnaire items may also give valuable information.

There has been increasing concern in recent years that non-smokers chronically exposed to tobacco smoke in their daily lives may suffer a significant risk to their health. Adults so exposed have been reported to have impaired lung function ${ }^{1}$ and an increased incidence of lung cancer. ${ }^{23}$ These findings have provoked a vigorous debate, ${ }^{45}$ but a number of important issues have not yet been adequately addressed. In particular, there has been little consideration of dosimetric aspects. ${ }^{6}$

Acute exposure of non-smokers to tobacco smoke, whether experimentally ${ }^{7}$ or in a natural setting, ${ }^{8}$ has been shown to result in absorption of smoke products. Increases in blood carboxyhaemoglobin $(\mathrm{COHb})$ of about $1 \%$ and in plasma nicotine level of $2.5 \mathrm{ng} / \mathrm{ml}$ have been reported, the equivalent of smoking one cigarette and less than one third of a cigarette respectively. However, since these levels resulted from acute exposure of limited duration, extrapolation to the chronic dose received from the variety of exposures in daily life is not possible. Few non-smokers are likely to be repeatedly and chronically subjected to passive exposure of this degree of severity. Nevertheless preliminary evidence indicates that the majority of non-smokers in the United Kingdom may have measurable amounts of tobacco specific chemicals in their body fluids. ${ }^{9}$
Epidemiological investigation of the risks of passive smoking required both a reliable non-invasive marker and validated questionnaire measures for assessing the degree of exposure. While $\mathrm{COHb}$ has been found to be of use in short term studies, it is not specific to tobacco smoke and may not be sufficiently sensitive to reflect the variety of exposures occurring in daily life. Thiocyanate may likewise suffer from a lack of specificity and sensitivity. Nicotine is specific to tobacco but has a short half life in plasma, and its major metabolite, cotinine, may provide a better guide. We have examined the levels of all these markers and their relation to self report by questionnaire in non-smokers whose exposure to tobacco smoke was not artificially manipulated in any way. The results have implications both for the choice of biochemical marker for the study of passive smoke exposure and for the validity of questionnaire measures of exposure.

\section{Subjects and methods}

The subjects were 100 non-smokers (mean age $56 \cdot 8$, SD 10.1) drawn from a sample of 215 patients attending cardiology and vascular outpatient clinics at St Mary's Hospital, London, who filled in a smoking questionnaire and provided samples of 
blood, expired air, saliva, and urine. The non-smokers were defined as those who reported no smoking of cigarettes, pipes or cigars and whose levels of plasma cotinine were below $20 \mathrm{ng} / \mathrm{ml}$. The latter requirement resulted in the exclusion of 21 self reported non-smokers whose levels of biochemical markers were similar to those found in the self-reported smokers and were therefore incompatible with their claimed non-smoking status (table 1).

Table 1 Mean values of biochemical measures in non-smokers, smokers and deceivers

\begin{tabular}{|c|c|c|c|}
\hline & $\begin{array}{l}\text { Non-smokers } \\
(n=100)\end{array}$ & $\begin{array}{l}\text { Smokers } \\
(n=94)\end{array}$ & $\begin{array}{l}\text { Deceivers } \\
(n=21)\end{array}$ \\
\hline Expired air CO (ppm) & $5 \cdot 6$ & $20 \cdot 8$ & $16 \cdot 4$ \\
\hline Carboxyhaemoglobin (\%) & 0.9 & $3 \cdot 9$ & $3 \cdot 2$ \\
\hline \multicolumn{4}{|l|}{ Nicotine (ng/ml) } \\
\hline Plasma & 0.9 & $14 \cdot 8$ & $12 \cdot 2$ \\
\hline Saliva & $4 \cdot 8$ & $672 \cdot 5$ & $168 \cdot 7$ \\
\hline Urine & $8 \cdot 3$ & $1749 \cdot 9$ & 998.6 \\
\hline \multicolumn{4}{|l|}{ Cotinine $(\mathrm{ng} / \mathrm{ml})$} \\
\hline Plasma & $1 \cdot 5$ & $275 \cdot 2$ & $239 \cdot 3$ \\
\hline Saliva & $1 \cdot 7$ & 309.9 & $244 \cdot 1$ \\
\hline Urine & $5 \cdot 0$ & $1391 \cdot 0$ & $887 \cdot 7$ \\
\hline \multicolumn{4}{|l|}{ Thiocyanate } \\
\hline Plasma $(\mu \mathrm{mol} / 1)$ & $50 \cdot 8$ & $122 \cdot 9$ & $117 \cdot 6$ \\
\hline Saliva (mmol/1) & $1 \cdot 30$ & $2 \cdot 45$ & $2 \cdot 39$ \\
\hline Urine $(\mu \mathrm{mol} / 1)$ & $74 \cdot 8$ & $154 \cdot 9$ & $113 \cdot 4$ \\
\hline
\end{tabular}

Passive smoke exposure was indexed by the response to the questionnaire item: "Have you been exposed to tobacco smoke from someone else in the past three days?" The response categories were: "Yes, a lot", "Yes, some", "Yes, a little", and "None at all".

The concentration of nicotine and cotinine in plasma, saliva, and urine was determined by gas chromatography. ${ }^{1011}$ Carboxyhaemoglobin concentrations were measured with an IL 282 $\mathrm{CO}$-oximeter and carbon monoxide in end-expired air after breath holding with a portable $\mathrm{CO}$ analyser incorporating an ethanol filter. ${ }^{12}$ Thiocyanate was measured by an automated modification of the Aldridge technique. ${ }^{13}$

\section{STATISTICAL ANALYSIS}

Since variables were skewed towards zero, they were subjected to square root transformation before analysis by $t$ test or analysis of variance. In the case of measures of cotinine, where a substantial minority of subjects had undetectable levels, it was thought more appropriate to use non-parametric tests (Kruskal-Wallis one-way analysis of variance and Mann-Whitney test).

\section{Results}

The mean concentration of each marker in the non-smokers, smokers, and deceivers is shown in table 1 . The average value in the deceivers was in each case much higher than in the non-smokers and did not differ significantly from the smokers' level for seven of the nine markers measured. The lowest concentration of plasma cotinine encountered in the deceivers was over three times higher than the highest in the non-smokers, and this subject also had a plasma nicotine concentration of $10.5 \mathrm{ng} / \mathrm{ml}$, close to the mean for all self-reported smokers. On average the concentration of cotinine, whether measured in plasma, saliva or urine, was about 200 times higher inf the smokers and the deceivers than in the non-smokers.

Table 2 shows for the non-smokers the mean concentration of each marker by degree of self reported smoke exposure. Almost half of the subjects reported no exposure at all in the past three days, and only $7 \%$ reported heavy exposure.

The concentration of cotinine in each body fluid 8 measured showed significant variation with exposure. This was not just due to a differenceo between those who reported any exposure versus?

Table 2 Mean values of biochemical measures in non-smokers by degree of self reported passive smoke exposure

\begin{tabular}{|c|c|c|c|c|c|}
\hline \multirow[b]{3}{*}{ Expired air $\mathrm{CO}(\mathrm{ppm})$} & \multicolumn{5}{|c|}{ Self reported passive smoke exposure } \\
\hline & \multirow{2}{*}{$\begin{array}{l}\begin{array}{l}\text { None } \\
(n=46)\end{array} \\
5 \cdot 7\end{array}$} & \multirow{2}{*}{$\begin{array}{c}\begin{array}{c}\text { A little } \\
(n=27)\end{array} \\
5.6\end{array}$} & \multirow{2}{*}{$\begin{array}{c}\begin{array}{l}\text { Some } \\
(n=20)\end{array} \\
5.6\end{array}$} & \multirow{2}{*}{$\frac{\begin{array}{c}\text { A lot } \\
(n=7)\end{array}}{5.0}$} & \multirow{2}{*}{$\begin{array}{l}\begin{array}{l}\text { Probability } \\
\text { value }\end{array} \\
\text { NS }\end{array}$} \\
\hline & & & & & \\
\hline Carboxyhaemoglobin (\%) & 0.94 & 0.81 & 0.80 & 0.80 & NS \\
\hline \multicolumn{6}{|l|}{ Nicotine (ng/ml) } \\
\hline Plasma & 1.04 & 0.76 & 0.72 & 0.90 & NS \\
\hline Saliva & $3 \cdot 81$ & $4 \cdot 80$ & 4.44 & $12 \cdot 12$ & $<0.05$ \\
\hline Urine & $3 \cdot 87$ & $12 \cdot 22$ & 11.92 & $12 \cdot 22$ & $=0.06$ \\
\hline \multicolumn{6}{|l|}{ Cotinine $(\mathrm{ng} / \mathrm{ml})$} \\
\hline Plasma & 0.82 & 1.81 & $2 \cdot 52$ & $1 \cdot 81$ & $<0.005$ \\
\hline Saliva & 0.73 & $2 \cdot 20$ & $2 \cdot 80$ & $2 \cdot 63$ & $<0.001$ \\
\hline Urine & $1 \cdot 55$ & $6 \cdot 50$ & $8 \cdot 65$ & $9 \cdot 36$ & $<0.001$ \\
\hline \multicolumn{6}{|l|}{ Thiocyanate } \\
\hline Plasma $(\mu \mathrm{mol} / 1)$ & $48 \cdot 1$ & $55 \cdot 5$ & $51 \cdot 7$ & $47 \cdot 4$ & NS \\
\hline Saliva (mmol/1) & $1 \cdot 27$ & $1 \cdot 50$ & 1.03 & $1 \cdot 51$ & NS \\
\hline Urine $(\mu \mathrm{mol} / 1)$ & $72 \cdot 8$ & $80 \cdot 3$ & $74 \cdot 2$ & $73 \cdot 1$ & NS \\
\hline
\end{tabular}

Note: Numbers differ somewhat for each variable because of missing data. 
those who reported none, since those who reported "some" or "a lot" tended to have higher levels than those who reported only "a little" (for cotinine in saliva and in plasma $p=0.06$ and for urine $p<0.01$ ). On average, those reporting the two highest levels of exposure had cotinine concentrations that were at least three times higher than the cotinine concentrations of those who reported no exposure at all. The concentrations of cotinine in the different body compartments sampled were highly intercorrelated (plasma-saliva $\mathrm{r}=+\mathbf{0 . 8 2}$; plasma-urine $r=+0.81$; saliva-urine $r=+0.91$ ). The distributions of individual values for these measures are shown in figure 1 .

Thiocyanate and carbon monoxide levels were unrelated to exposure, as was the concentration of nicotine in plasma. However, salivary nicotine concentration increased in a linear fashion with exposure (linear $\mathbf{F} 7.86$ df $1,90 \mathrm{p}<0.01$ ). The concentration of nicotine in urine just failed to show significant variation across all four self report categories $(p=0.06)$, but after collapsing across categories there was a significant difference in mean level between those who reported no exposure and those who reported some $(3.9 v 12 \cdot 1 \mathrm{ng} / \mathrm{ml}, t=2 \cdot 95$ $\mathrm{p}<0 \cdot 005)$.

\section{TIME OF DAY}

Our questionnaire item asked about exposure over the past three days. However, it is possible that some markers (particularly nicotine) might reflect recent exposure but not that occurring on previous days. To test if this might be the case, subjects seen in afternoon clinics (whose most recent exposure would be more likely to be on the day in question) were compared with those who had attended in the morning (whose most recent exposure would be more likely to be on the previous day). We found that the concentration of nicotine in saliva was significantly higher in those attending in the afternoon $(5.65 v 3.35 \mathrm{ng} / \mathrm{ml}$ in morning attenders, $t=2.53 \mathrm{p}=0.01)$, and only in this subgroup was the relation between level and self reported passive exposure present (fig 2).

For the other variables there was no clearcut relation between time of day and the measured concentration, although there was a tendency for plasma cotinine levels to be higher in afternoon attenders $(p=0.056)$.

\section{Discussion}

This study shows that cotinine can provide a sensitive guide to the extent of recent daily life passive smoke exposure in stringently defined non-smokers. The concentration of this marker was systematically related to self report of the degree of exposure over
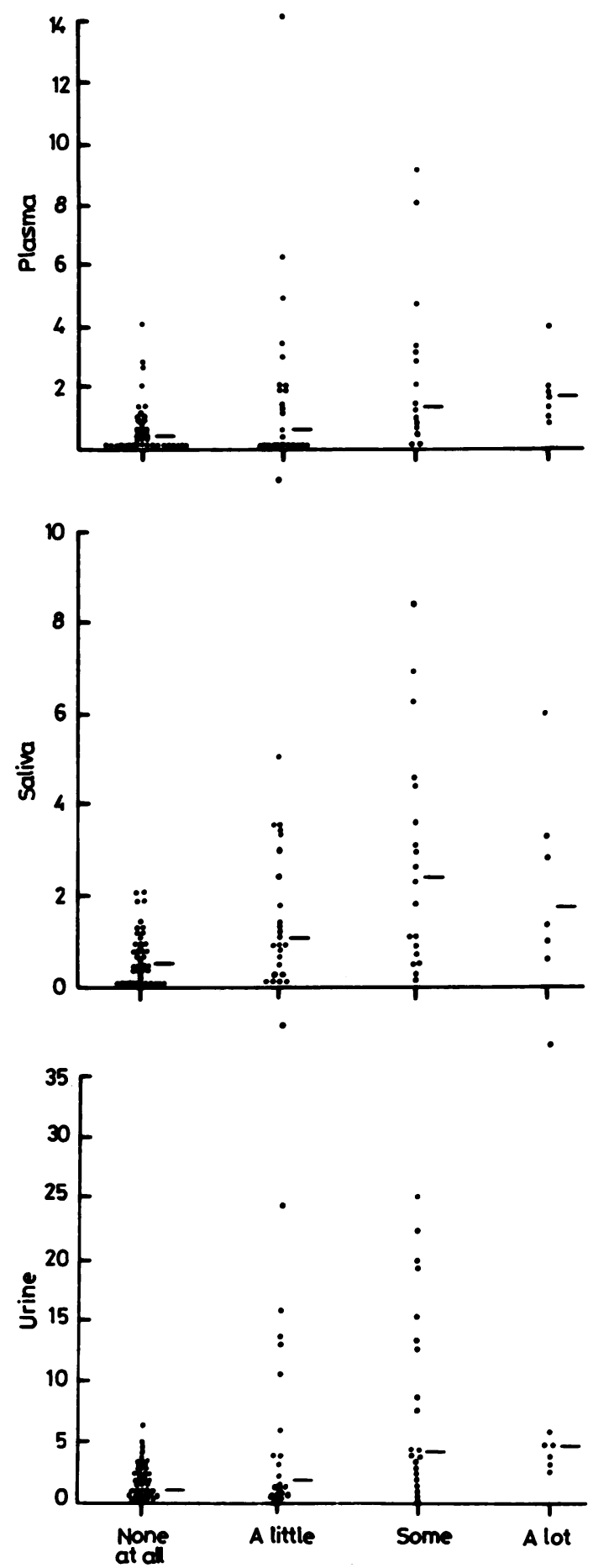

Fig 1 Distributions of cotinine concentrations ( $\mathrm{ng} / \mathrm{ml})$ in plasma, saliva, and urine by degree of self reported passive smoke exposure. Horizontal bars indicate median values. 


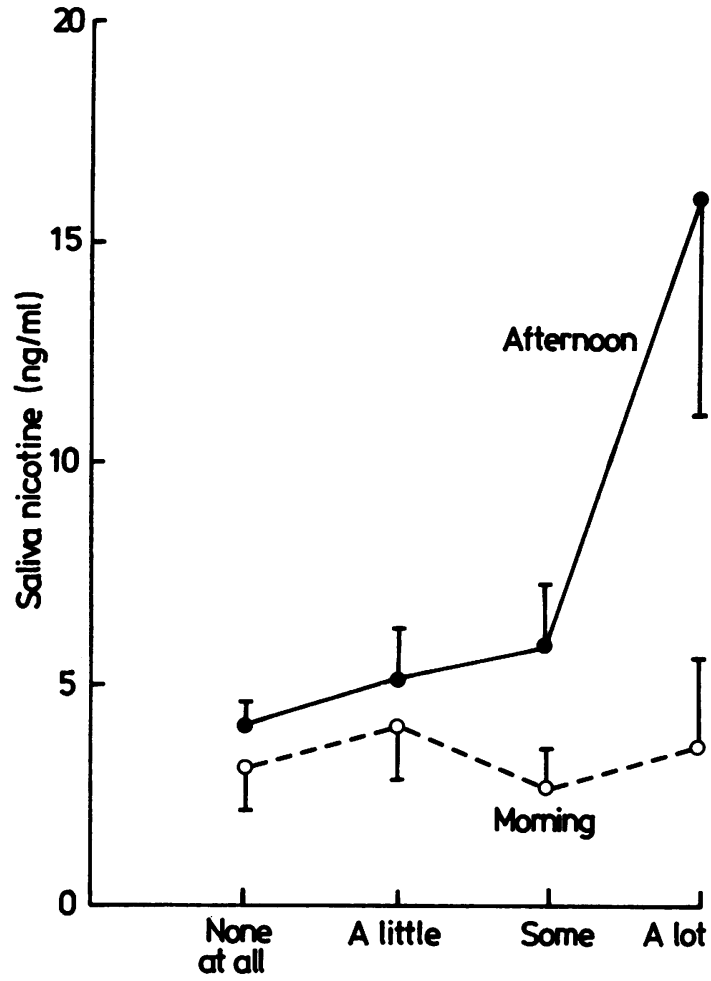

Fig 2 Saliva nicotine concentrations by degree of self reported passive smoke exposure in morning and afternoon attenders (mean $\pm \mathrm{SE})$.

the past three days. Furthermore, non-invasive samples of saliva and urine provided essentially the same information as did invasive and less easily gathered blood samples and for epidemiological applications may be preferable. Our data showed a high degree of intercorrelation between the concentration of cotinine in urine and saliva and do not permit a recommendation of one sample over the other. However, we note two recent publications which indicate that urinary cotinine may be the marker of choice. ${ }^{14} 15$

Nicotine measures also showed some relation to self reported exposure, although not in plasma and only marginally in urine. The concentration of nicotine in saliva was related to exposure, but only exposure on the day of testing. These differences reflect the metabolism and excretion of nicotine. Nicotine in plasma has a short half-life at about 2 hours, being metabolised to cotinine, which has a half-life in non-smokers of about 12 hours, ${ }^{16}$ and being concentrated and excreted in saliva and urine.

Exclusion of subjects whose self reported smoking status was at variance with their measured concentrations of biochemical markers was necessitated by the problem of deception among patients attending clinics through smoking related disease. Although categorisation of the "deceivers" was by reference only to plasma cotinine, it is important to note that they had raised values of all markers measured. Comparison with data from experimental studies of exposure to abnormally smoky atmospheres shows that markers are raised, but still only by a small fraction of the active smoking dose. Jarvis et al estimated that after 2 hours' exposure in a very smoky public house only between one tenth and one third of one cigarette-equivalent of nicotine had been absorbed. ${ }^{8}$ It is therefore biologically implausible that a pattern of markers consistently raised to levels similar to those in active smokers could be seen in passive smokers, however chronically exposed. Furthermore, we stress that the exclusion of the deceivers was conservative with repect to establishing a relation between measures of smoke absorption and self reported passive exposure, since they typically reported high levels of passive exposure ("A lot" 10: "Some" 6; "Just a little" 2; "None at all" 3 ).

The mean levels of each biochemical marker in this sample of non-smokers were low. Average cotinine and nicotine concentrations were similar to those found in a group of non-smokers who had been specifically requested to avoid all contact with tobacco smoke in the day before sampling, ${ }^{8}$ and the concentration of nicotine in urine and saliva in those who attended in the afternoon was about $50 \%$ lower than Feyerabend $e t a l^{9}$ found in non-smokers on the afternoon of a normal working day. This probably reflects the fact that the present sample consisted mainly of elderly subjects, many of whom led restricted lives because of chronic illness. That clear relations between self reported exposure and smoke absorption emerged despite this range restriction suggests that such effects might be stronger in more representative samples.

The average concentration of cotinine, whether measured in plasma,saliva or urine, lay between one third and one half of $1 \%$ of the levels found in the smokers in this study and might therefore be regarded as trivial. However, since a dose-response relation to passive exposure was found, some individuals had received a higher proportion of a smoking dose, and it is possible that they may have received larger, and clinically more significant, doses of compounds which we did not measure. For example, although the concentration of nicotine in 
sidestream smoke is about three times that in mainstream, the ratios are particularly high, up to 10 , in the case of various carcinogenic nitrosamines. ${ }^{17}$

Epidemiological studies of the health risks of passive smoking have at best used global self-report to categorise non-smokers as exposed or non-exposed, and in some cases have used indirect inference. For example, in the important Japanese study, ${ }^{2}$ wives' status as exposed or non-exposed was inferred from their husbands' smoking habits, and the degree of exposure of the wife was crudely indexed by the number of cigarettes her husband smoked per day. The potential for misclassification that this method poses is indicated by the fact that a recent study found that $30 \%$ of persons married to smokers reported no passive smoke exposure. ${ }^{18}$ These observations throw doubt on the accuracy of categorisation by inference. Nevertheless the present data suggest that detailed questions about recent exposure provide valid information and can usefully supplement the information gained from biochemical markers.

We conclude that valid non-invasive markers of passive exposure to tobacco smoke in non-smokers are available and should be used in epidemiological investigations of the health risks of passive smoking. They can usefully be supplemented by detailed questionnaire measures.

The financial support of the Medical Research Council is gratefully acknowledged and also that of the Joint Research Board of St Bartholomew's Hospital.

\section{References}

${ }^{1}$ White JR, Froeb HF. Small airways dysfunction in non-smokers chronically exposed to tobacco smoke. New Eng J Med 1980; 302: 720-3.
${ }^{2}$ Hirayama T. Non-smoking wives of heavy smokers have a higher risk of lung cancer: a study from Japan. $\mathrm{Br} \mathrm{Med} J$ 1981; 282: 183-5.

${ }^{3}$ Trichopoulos D, Kalandidi A, Sparros L, McMahon B. Lung cancer and passive smoking. Internat $J$ Cancer 1981; 27: 1-4.

${ }^{4}$ Editorial. Passive smoking: Forest, Gasp, and facts. Lancet 1982; i: 548-9.

${ }^{5}$ Rossiter CE. Passive smoking. Lancet 1982; i: 1356.

${ }^{6}$ Lee PN. Passive smoking. Fd Chem Toxic 1982; 20: 223-9.

${ }^{7}$ Russell MAH, Cole PV, Brown E. Absorption by non-smokers of carbon monoxide from room-air polluted by tobacco smoke. Lancet 1973; i: 576-9.

${ }^{8}$ Jarvis M, Russell MAH, Fayerabend C. Absorption of nicotine and carbon monoxide from passive smoking under natural conditions of exposure. Thorax 1983; 38: 829-33.

${ }^{9}$ Feyerabend C, Higgenbotham T, Russell MAH. Nicotine concentrations in urine and saliva of smokers and non-smokers. Br Med J 1982; 284: 1002-4.

${ }^{10}$ Feyerabend C, Russell MAH. Assay of nicotine in biological materials sources of contamination and their elimination. J Pharm Pharmacol 1980; 32: 178-81.

${ }^{11}$ Feyerabend C, Russell MAH. A rapid gas-liquid chromatographic determination of cotinine in biological fluids. Analyst 1980; 105: 993-1001.

${ }^{12}$ Jarvis MJ, Russell MAH, Saloojee Y. Expired air carbon monoxide: a simple breath test of tobacco smoke intake. Br Med J 1980; 281: 484-5.

${ }^{13}$ Saloojee Y, Vesey CJ, Cole PV, Russell, MAH. Carboxyhaemoglobin and plasma thiocyanate: complementary indicators of smoking behaviour? Thorax 1982; 37: 521-5.

${ }^{14}$ Wald NJ, Boreham J, Bailey A, Ritchie C, Haddow JE, Knight G. Urinary cotinine as a marker of breathing other people's tobacco smoke. Lancet 1984; i: 230-1.

${ }^{15}$ Greenberg RA, Haley NJ, Etzel RA, Loda FA. Measuring the exposure of infants to tobacco smoke. $N$ Eng J Med 1984; 310: 1075-8.

${ }^{16}$ Kyerematen GA, Damiano MD, Dvorchik BH, Vesell ES. Smoking-induced changes in nicotine disposition: Application of a new HPLC assay for nicotine and its metabolites. Clin Pharmacol Ther 1982; 32: 769-80.

${ }^{17}$ US Department of Health, Education and Welfare. Smoking and health: A report of the Surgeon General, Washington, DC: US Public Health Service, 1979.

${ }^{18}$ Friedman GD, Petitti DB, Bawol RD. Prevalence and correlates of passive smoking. Am J Public Health 1983; 73: 401-5. 